\title{
Transfer of single- and double-alternation patterning as a function of odor cues
}

\author{
ROBERT E. PRYTULA \\ Middle Tennessee State University, Murfreesboro, Tennessee 37132 \\ STEPHEN F. DAVIS \\ Emporia State University, Emporia, Kansas 66801 \\ and \\ DAYLE D. ALLEN and R. CLAY TAYLOR \\ Austin Peay State University, Clarksville, Tennessee 37140
}

\begin{abstract}
Two squads of rats were initially given single-alternation (SA) training and subsequently shifted to a double-alternation (DA) schedule. Two other squads were initially trained under a DA schedule and shifted to a SA schedule. The results showed that there was no persistence of behavior learned under one schedule to the new schedule. (Performance conformed appropriately and virtually immediately to the new schedule.) These results suggest that contemporary odor conditions may be very salient cues in situations involving transferring behavior from one schedule of reinforcement to another.
\end{abstract}

Rats that have been exposed to alternating sequences of rewards and nonrewards (e.g., single alternation, SA, and double alternation, DA) run fast on the rewarded (R) trials and slowly on the nonrewarded $(\mathrm{N})$ trials (see Bloom \& Capaldi, 1961; Capaldi, 1966, 1967, 1971; Capaldi \& Stanley, 1963; Franchina \& Kaiser, 1971). According to sequential theory (Capaldi, 1966, 1967, 1971), it is assumed that $\mathrm{R}$ and $\mathrm{N}$ events occasion distinctive internal memory stimuli. These $\mathrm{R}$ and $\mathrm{N}$ memories persist from trial to trial and may become conditioned to the instrumental response, thereby forming the effective stimulus complex controlling responding. For example, under SA training, slow responding on $\mathrm{N}$ trials develops because the memory of the preceding reward event predictably signals nonreward and acquires an inhibitory influence. Conversely, a running response made in the presence of an $\mathrm{N}$-event memory leads to faster performance on the $\mathrm{R}$ trials, an excitatory influence.

Recent research on SA training has been concerned with identifying and controlling other factors that might account for the patterning of behavior. Among such cues, Surridge and Amsel (1965a, 1965b) have suggested that differential responding might be mediated by olfactory cues, the presence or absence of food odor as the rat approaches the goal area, or cues arising from differential handling of the subjects by the experimenter

This research was supported by a Faculty Research Grant from Middle Tennessee State University. Portions of this paper were presented at the Annual Meeting of the Southwestern Psychological Association, San Antonio, Texas, April 1979. The authors also thank Larry R. Stanley for his comments in the preparation of this manuscript. on the $\mathrm{R}$ and $\mathrm{N}$ trials. Using apparatus that eliminated both handling and food cues, Hanford and Zimmerman (1969) and Harris and Thomas (1966) have found distinct pattern responding. Less clear, however, is the influence of odors exuded by previously run subjects. Amsel, Hug, and Surridge (1969) demonstrated that SA patterning was to some extent mediated by odor cues from previously run animals. Research in the area of DA training and other schedules strongly suggests that rats exude distinctive odors, at least on the $\mathrm{N}$ trials, that can serve as cues for differential responding by other rats on subsequent trials (e.g., Bloom \& Phillips, 1973; Davis, Prytula, Noble, \& Mollenhour, 1976; Ludvigson \& Sytsma, 1967; Prytula \& Davis, 1974, 1976). Moreover, this research suggests that unless some external cue, such as odor (Ludvigson \& Sytsma, 1967) or a systematic light cue (Seago, Ludvigson, \& Remley, 1970) or alley color (Capaldi, 1971), is available, rats do not appear capable of learning the DA sequence. Although the role and influence of odor as a cue in controlling behavior under DA schedules have received considerable empirical support, Mackintosh (1974), as well as Capaldi (1971), appears to assign it only a minor role.

The literature on SA training would strongly suggest that this behavior is controlled predominantly by the memory of R and $\mathrm{N}$ events (see Capaldi, 1966, 1967, 1971; Flaherty \& Davenport, 1972; Franchina \& Kaiser, 1971; Hanford \& Zimmerman, 1969; Harris \& Thomas, 1966). According to the sequential theory, animals trained under a SA schedule should transfer behavior learned under this schedule to and through other schedules. For example, Bloom and Capaldi (1961) 
reported that prior established SA patterning persisted and transferred through the initial block of a DA schedule. Less strong was the DA-to-SA transfer, but Bloom and Capaldi (1961) maintained that performance under the SA schedule was related to prior DA training. Likewise, Franchina and Kaiser (1971) found that SA performance transferred through nonalternating training schedules (i.e., SA patterning was evidenced under random and continuous training schedules). Therefore, the purpose of the present experiment was to assess the relative saliency of odor vs. memory as cues in the control of pattern responding. If memory is the most salient cue in SA responding, then one would expect that groups of animals given initial SA training would persist in this behavior when shifted to a DA schedule (see Bloom \& Capaldi, 1961; Franchina \& Kaiser, 1971). However, if odor cues are maximized and hence become more salient, the animals should immediately change their behavior to coincide with the schedule in effect; that is, there should be an immediate shift to DA patterning. Shifting from a DA schedule to a SA schedule should lead to either a weak persistence of DA patterning or nondifferential responding if the memory of prior DA training affects performance (Bloom \& Capaldi, 1961). As in the case of the SA-to-DA shift, odor theory would predict an immediate shift to SA patterning.

To test these apparently opposing predictions, two squads of rats were initially given SA training and subsequently shifted to a DA schedule. Two other squads were initially trained on a DA schedule and shifted to a SA schedule.

\section{METHOD}

\section{Subjects}

Twenty-eight 90-day-old male albino rats purchased from the Holtzman Company, Madison, Wisconsin, served as subjects. All subjects were individually caged with water available on an ad-lib basis. One week prior to the start of pretraining, all subjects were placed on a food-deprivation regimen that maintained them at $85 \%$ free-feeding body weight. This deprivation schedule remained in effect for the duration of the experiment.

\section{Apparatus}

The apparatus consisted of a single straight runway $(11.4 \mathrm{~cm}$ wide $\times 12.7 \mathrm{~cm}$ high), with a gray startbox $(28.1 \mathrm{~cm})$, a black run section $(91.4 \mathrm{~cm})$, and a black goalbox $(30.5 \mathrm{~cm})$. Masonite guillotine doors separated the startbox and goalbox from the run section. Pine lumber (.5 in.) was used in constructing the apparatus. Gloss enamel paint was used in all cases. Start, run, and goal times, produced by the activation of a microswitch located on the start door and the interruption of a series of photoelectric cells (located $15.2,92.4$, and $116.8 \mathrm{~cm}$ beyond the start door, respectively), were recorded on all trials. A plastic receptacle recessed into the end wall of the goalbox served as the goal cup. To help insure that nondifferential food odors existed between $\mathrm{R}$ and $\mathrm{N}$ trials, the dispenser tube from a loaded pellet dispenser was inserted into the goal cup. A thin sheet of transparent plastic covered the top of the alley to prevent odors from dissipating.

\section{Design and Procedure}

Two equal groups $(n=14)$ were randomly formed at the beginning of pretraining. Each group was further subdivided into two equal squads $(n=7)$ and assigned a permanent number (running order) within the squad. A 4-day pretraining period immediately preceded the experiment proper. Pretraining Days 1 and 2 consisted of handling and taming. On pretraining Days 3 and 4 , each subject received a 5 -min exploration period in the unbaited apparatus with all photoelectric equipment operative. Subjects were habituated to the $45-\mathrm{mg}$ Noyes reward pellets in the home cage on all pretraining days.

Experimental testing was divided into two phases. During Phase 1 , all subjects in the SA squads received a SA (RNRNRN RN) schedule of 8 trials/day. Subjects in the DA squads received a DA (RRNNRRNN) schedule of 8 trials/day. Phase 1 training lasted for 13 days for one SA and one DA squad and 15 days for the remaining SA and DA squads.

Following Phase 1 training, each SA squad was shifted to the DA schedule, and each DA squad was shifted to the SA schedule. This shift was staggered such that two squads (one SA and one DA) were shifted after 13 days of the training and the other squads (one SA and one DA) were shifted after 15 days of training. Thus, a staggered intervention design was employed. Phase 2 lasted 2 days. In all cases, $1245 \mathrm{mg}$ pellets were present on $\mathrm{R}$ trials. On $\mathrm{N}$ trials subjects were confined to the empty goal box for $30 \mathrm{sec}$.

On all days all subjects within a squad received Trial 1 before Trial 2 was administered, and so on. Each subject was randomly assigned a permanent running-order position within the squad, and the running of squads each day was randomly determined. Before Trial 1 and after the running of each subsequent trial for a squad, the alley was thoroughly swabbed and aired for $5 \mathrm{~min}$. By Day 7 of Phase 1, the intertrial interval for all squads was approximately 10-12 $\mathrm{min}$.

\section{RESULTS}

\section{Statistical Procedures}

A squads by R-N by days analysis of variance was performed on the data from the last 2 days of Phase 1 and the 2 days of Phase 2. Significant effects were further investigated using the Newman-Keuls procedure. The data from the first subject in each squad were not included in the statistical analysis since these subjects were donor animals for the remaining subjects of the squad.

\section{SA-to-DA Transfer}

Statistical analysis of goal measure speeds corroborates the graphical impression (see Figure 1) that SA subjects readily developed strong pattern responding in this measure during Phase 1 [R-N, $F(7,70)=24.71$, $p<.01]$. Further comparisons revealed that none of the $R$ trials differed significantly from each other and neither did the $\mathrm{N}$ trials. However, $\mathrm{R}$ trials differed significantly from $\mathrm{N}$ trials ( $\mathrm{ps}<.01$ ). Patterned responding was not observed in either start or run measures.

The first subject in each SA squad did not learn the schedule; as can be seen in Figure 1, they responded nondifferentially throughout the course of training. A distinct Subject by Position effect within the squad was also obtained. Subjects 2,3 , and 4 ran significantly faster on the $N$ trials than Subjects 5, 6, and $7(p<.01)$. As nonreward odor accumulated in strength over subjects, the latter subjects responded slower.

Shifting the subjects from a SA to a DA schedule led to an immediate change in responding; they immediately 


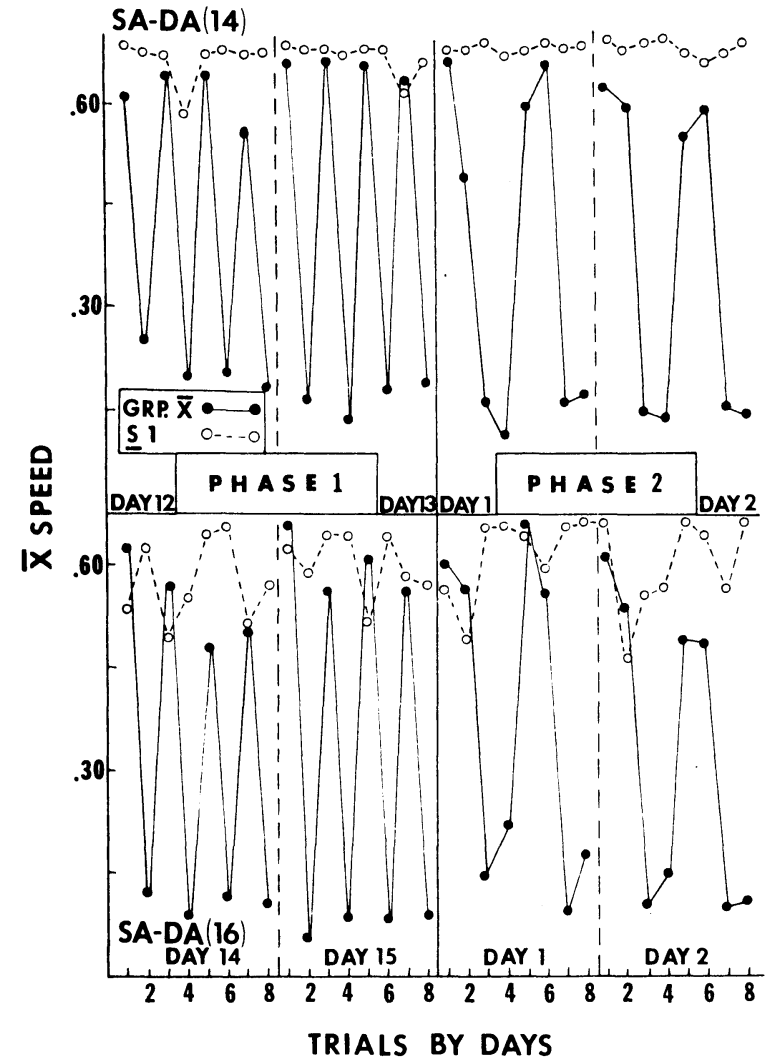

Figure 1. Mean goal speeds, $R$ and $N$ trials by days for the first subject of each squad (open circles, dashed lines) and the remaining members of each squad (solid circles and lines). Represented in the upper panel is the first subject and squad that were transferred to the DA schedule after Day 13; the bottom panel represents the first subject and squad that were transferred after Day 15.

switched their behavior in order to coincide with the DA schedule $\quad[R-N, F(7,70)=14.56, p<.01]$. Further comparisons revealed that the $\mathrm{R}$ trials did not differ from each other, and all $\mathrm{R}$ trials differed significantly from all $\mathrm{N}$ trials $(\mathrm{ps}<.01$ ). This immediate change in behavior was clearly evident by Trial 2; SA subjects should have run slowly on this trial, since they did not know the schedule had changed until reaching the goal area. If memory had been controlling behavior, there should have been at least some persistence of this SA behavior into some of the trials of the DA schedule; this was not obtained. Similarly, as in Phase 1, the first subject of each squad responded nondifferentially.

\section{DA-to-SA Transfer}

As can be seen in Figure 2, DA subjects readily developed patterned responding in the goal measure during Phase 1 [R-N, $F(7,70)=17.64, p<.01]$. Comparisons revealed that $\mathrm{R}$ trials did not differ significantly from each other, $\mathrm{N}$ trials did not differ from each other, and $\mathrm{R}$ trials differed significantly from $\mathrm{N}$ trials (ps<.01). As with SA responding, the first subject in each DA squad did not learn the sequence. A Subject by Position effect slow-down was likewise obtained;
Subjects 2,3 , and 4 ran significantly faster on the $\mathrm{N}$ trials than Subjects 5,6 , and $7(p<.01)$.

Shifting the subjects from a DA schedule to a SA schedule led to an immediate acquisition of SA patterning. This change in behavior was evident by Trial 2; DA subjects should have run fast on the second trial of the sequence. They did not; they immediately slowed down $[R-N, F(7,70)=43.92, p<.01]$. Further comparisons revealed that $\mathrm{R}$ trials did not differ from each other, $\mathrm{N}$ trials did not differ from each other, and all $\mathrm{R}$ trials differed significantly from all $\mathrm{N}$ trials (ps $<.01$ ). As under the SA schedule, the first subject in each DA squad responded nondifferentially; they did not learn the schedule. On the basis of past research, one would have expected that memory would have persisted longer, but this was not the case.

\section{DISCUSSION}

The present results show that animals trained under a SA schedule and subsequently shifted to a DA schedule immediately (by the second trial) displayed DA patterning. Likewise, animals trained under a DA schedule and subsequently shifted to a SA schedule immediately displayed SA patterning. As the order of running subjects allowed the utilization of odor cues, the results strongly suggest that contemporary odor conditions were quite

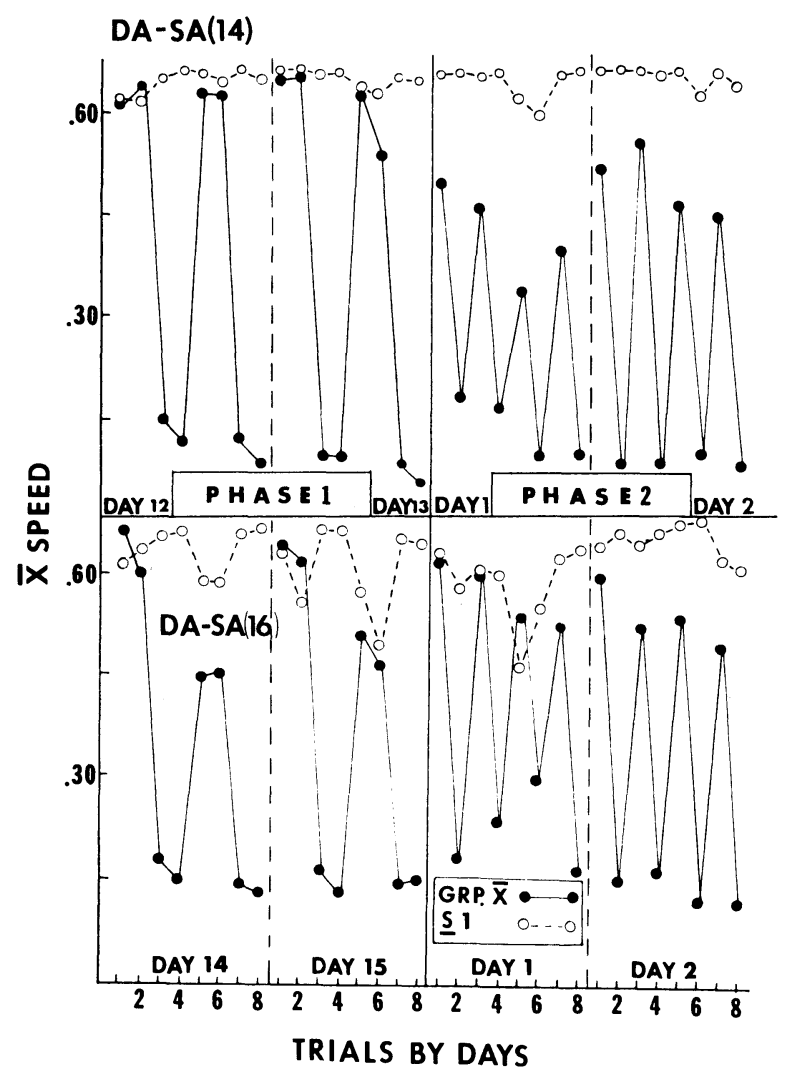

Figure 2. Mean goal speeds, $R$ and $N$ trials by days for the first subject of each squad (open circles, dashed lines) and the remaining members of each squad (solid circle and lines). Represented in the upper panel is the first subject and squad that were transferred to the SA schedule after Day 13; the bottom panel represents the first subject and squad that were transferred after Day 15. 
important in mediating these shifts in behavior. Additional support for this assumption is evidenced by several facts: (1) The first subject in each squad did not learn the schedules during either phase of the experiment. As these subjects were always tested in a clean (swabbed) runway, they can be considered to be "odor donors" for the remaining members of a squad. On the other hand, the fact that these subjects were run first in a squad should not have influenced memory processes relative to other members of the squad. Theoretically, these subjects should have also evidenced some learning under the SA schedule on the basis of memory (see Mackintosh, 1974). (2) A running-order position effect was obtained. In other words, in all squads Subjects 2, 3 , and 4 ran significantly faster than Subjects 5,6 , and 7 on the $\mathrm{N}$ trials. Due to the accumulation of odor from previous subjects, this slowing effect would be predicted by odor theory. However, it would not be anticipated if only memory processes were involved. (3) No SA or DA responding was observed in either start or run measures. Some memory of $\mathrm{R}$ and $\mathrm{N}$ events should also be functional, and result in differential responding, in these sections of the apparatus. As odors are predicted to accumulate at the point of maximum frustration (i.e., the goalbox), this observed nondifferential responding in the start and run measures is quite predictable by odor theory.

According to Capaldi (1971), the greater the similarity between schedules, the greater the amount of transfer observed when shifting from one schedule to another. Due to the similarity of the SA and DA schedules used in the present study, it would appear reasonable to have anticipated transfer, similar to that found by Bloom and Capaldi (1961). An even greater amount of transfer than that reported by Franchina and Kaiser (1971) might also have been predicted. In the Franchina and Kaiser (1971) study, SA patterning transferred through random and continuous schedules. As such transfer was not observed in the present study, it would appear reasonable to suggest that odor cues may be potentially more salient to the rat than memory cues. On the other hand, it should be recalled that the present study was specifically designed to maximize the presence and utilization of odor cues. In view of this, it may not be prudent to assume that odor cues and memory cues were afforded an equal opportunity for effective present experimental design. For example, the use of the 10-12-min intertrial interval might have reduced the effective memory of reward and nonreward for transfer. Two of the studies reporting transfer (Bloom \& Capaldi, 1961; Franchina \& Kaiser, 1971) employed intertrial intervals that were considerably shorter.

Hence, the main point brought out by the present data would appear to be that when odor cues are maximized, behavior is easily and lawfully brought under their control. This is well reflected in the immediate shift in patterned behavior shown by Trial 2 in Phase 2 . Memory cues may well be, and probably are, effective in certain conditions. However, the present data suggest the need to rule out the presence of odor before the nature and operation of such memory cues can be directly addressed.

\section{REFERENCES}

Amsel, A., Hug, J. J., \& Surridge, C. T. Subject-to-subject trial sequence, odor trails, and patterning at 24-h ITI. Psychonomic Science, 1969, 15, 119-120.

Bloom, J. M., \& CApaldi, E. J. The behavior of rats in relation to complex patterns of partial reinforcement. Journal of Comparative and Physiological Psychology, 1961, 54, 261-265.

Bloom, J. M., \& Phillips, J. M. Conspecific odors as discriminative stimuli in the rat. Behavioral Biology, 1973, 8, 279-283.

Capaldi, E. J. Partial reinforcement: A hypothesis of sequential effects. Psychological Review, 1966, 73, 459-477.

CAPALdi, E. J. A sequential hypothesis of instrumental learning. In K. W. Spence \& J. T. Spence (Eds.), The psychology of learning and motivation: Advances in theory and research (Vol. 1). New York: Academic Press, 1967.

Capaldi, E. J. Memory and learning: A sequential viewpoint. In W. K. Honig \& P. H. R. James (Eds.), Animal memory. New York: Academic Press, 1971.

Capaldi, E. J., \& Stanley, L. R. Temporal properties of reinforcement aftereffects. Journal of Experimental Psychology, 1963, 65, 169-175.

Davis, S. F., Prytula, R. E., Noble, M. J., \& Mollenhour, M. N. Motivational specificity of the signal value of odor cues. Animal Learning \& Behavior, 1976, 4, 407-410.

Flaherty, C. F., \& Daven port, J. W. Successive brightness discrimination in rats following regular versus random intermittent reinforcement. Journal of Experimental Psychology, 1972, 96, 1-9.

Franchina, J. J., \& Kaiser, P. Acquisition, transfer, and reacquisition of single-alternation responding in the rat. Journal of Comparative and Physiological Psychology, 1971, 76, 256-261.

Hanford, P. V., \& Zimmerman, J. Differential running in rats under an alternating (FR2) schedule in an automated runway. Psychonomic Science, 1969, 14, 107-108.

Harris, J. H., \& Thomas, G. J. Learning single alternation of running speeds in a runway without handling between trials. Psychonomic Science, 1966, 6, 329-330.

Ludvigson, H. W., \& Sytsma, D. The sweet smell of success: Apparent double alternation in the rat. Psychonomic Science, 1967, 9, 283-284.

Mackintosh, N. J. The psychology of animal learning. New York: Academic Press, 1974.

Prytula, R. E., \& Davis, S. F. Runway performance as a function of positively and negatively correlated olfactory cues. Psychological Reports, 1974, 35, 735-740.

Prytula, R. E., \& Davis, S. F. The relationship between locus of odor cues and double-alternation responding in the rat. Animal Learning \& Behavior, 1976, 4, 352-356.

Seago, J. D., Ludvigson, H. W., \& Remley, N. R. Effects of anosmia on apparent double-alternation in the rat. Journal of Comparative and Physiological Psychology, 1970, 71, $435-442$.

Surridge, C. T., \& Amsel, A. A “patterning”" effect that seems unrelated to after-effects from reward and nonreward. Psychonomic Science, 1965, 3, 373-374. (a)

Surridge, C. T., \& Amsel, A. Performance under a single alternation schedule of reinforcement at 24 -hour intertrial intervals. Psychonomic Science, 1965, 3, 131-132. (b)

(Received for publication December 5, 1979.) 